\section{Health and Disease}

SIR,-Mr. G. Teeling-Smith's paper on "Does the Conquest of Disease Matter?" (21 March, p. 762) betrays, I think, a very prevalent attitude amongst those closely associated with the pharmaceutical profession and indeed many physicians deeply immersed in the problems of curing disease.

It is right and proper that they should from time to time sing the praises of pharmacological advances and point with some pride to the falling death-rates from this or that disease. Improved vital statistics portray the results in numerical form of the operation of many factors working to eliminate disease, and it is not unnatural that those handling the tools of pharmacology should exaggerate the achievements of their handiwork and sometimes fail to appreciate and give credit to many social and environmental factors which have over the years contributed in no mean measure to these improved indices. It is not, however, this aspect of Mr. Teeling-Smith's paper which concerns me but rather his more philosophical excursions.

The Director of Health Economics appears to pass with great facility-and here I quote two of the consecutive captions-from "Cost of Conquest of Disease" to "Benefits of Good Health," rather in the manner of enumerating the sequential development of a geometrical proposition. Unfortunately the Euclidean logic is absent, for I suggest that "good health" is not a corollary of " banished disease," nor are they necessarily stages in an ordered progression. This fallacious inference is widely but uncritically accepted, but a little thinking will soon expose its falsehood. It no doubt springs from the least desirable definition of " health "-namely, " an absence of disease." Disease is a very ill-defined entity; it has neither a precise time of commencement, nor can the moment of its departure be documented, but in favourable circumstances it fades into a no-man's-land where its symptoms are forgotten.

Good health is that state of physical wellbeing which is coupled with the liberation of an individual's maximum mental and physical capacity. Drugs have no part in promoting such a concept and they are foreign to its maintenance. What proportion of the population achieve " good health" as thus defined is unknown, but is hardly likely to be a very large number.

The lesson of Mr. Teeling-Smith's paper is, I suggest, this. Many diseases have been conquered by various agencies, but this is by no means synonymous with asserting that a state of good health in the nation has been achieved. The very title of $\mathrm{Mr}$. TeelingSmith's paper hints that these achievements are somehow falling short of expectations. The conquest of disease is merely stage one in the achievement of "good health," and stage two begins by forgetting drugs, medicines, and the impedimenta of therapeutics and pursuing health by the rational control of ourselves and our manner of living. It is this stage two in our progress towards what is sometimes termed "positive health" which is best pictured by the Director of Health Economics when he says, "It is sometimes said that the attainment of higher standards of health may be encouraged by a supreme ignorance of one's functional bodily mechanisms and the chemical agents that are used to modify them"-a quotation not unfamiliar to me.

Let me finally quote where $\mathrm{Mr}$. TeelingSmith left off and say:

"In an era where the pill, antibiotic, tablet, syringe, and needle are given considerable prominence in medical and lay circles, it is well to bear in mind what some of the older and wiser physicians recognized and practised, and might well be practised more frequently to-day. They realized that the human body, given suitable circumstances, was itself a better performer whether in the field of immunology or therapeutics than any one of our artificial and chemical aids, or indeed all of them together, and that the wise and intelligent use of medicaments should on no account be a substitute for, or an obstruction to, the human organism in its natural progress towards recovery." - I am, etc.,

$$
\begin{aligned}
& \text { Health Office, } \\
& \text { Ashton-under-Lyne, } \\
& \text { Lancs. }
\end{aligned}
$$

Alan S. Simpson

\section{Smoking and Drinking Habits}

SIR,-There is an old adage, "When in doubt never commit yourself, committee yourself." The Government is a past master in the art.

The projected inquiry into the smoking habits of young people seems slightly indecent. It is the avowed aim of the tobacco and drink trades to increase consumption by establishing smoking and drinking as a necessary social activity. Young people do not haul themselves up by their own boot-straps; they absorb the customs of the society in which they grow up. The enormous advertising expenditure of these trades involves, and this was a declared aim of the brewers before the war, the inculcation of the drinking habit into the young so that they may grow up to be the mainstay of the publichouse. The Society of Friends published this presidential declaration before the war and were rebuked for divulging opinions expressed at a private banquet.

Rather than inquire into the problem, "Why young people smoke," would it not be better to ask a few preliminary questions: (1) Why do tobacco firms advertise? (2) What are the main themes of their advertising ? (3) At whom is their advertising directed?

Presumably there are good reasons for spending vast sums on advertising. Teenagers are a main market. Children look ahead and imitate. What hypocrites we are ! -I am, etc.,

Farnham Royal, M. E. M. HERFORD.

Bucks.

\section{Phenacetin Abused}

SIR,-With reference to the letter by $\mathrm{Dr}$. Robert John in the B.M.F. (14 March, p. 698), cases of "phenacetin nephritis" recorded in the literature have admittedly followed ingestion of drug mixtures, but the drug common to all has been phenacetin.

The pros and cons of this problem are fully discussed in $A$ Review and Ribliography of
"Analgesic Abuse" published by Burroughs Wellcome and Co. (U.S.A.) Inc., who give a list of the formulas involved in excessive use. For simplicity of argument we may take three of these: (1) Acetylsalicylic acid, phenacetin, caffeine (A.P.C. and similar preparations); (2) Acetylsalicylic acid, phenacetin, codeine (Tabs. Cod. Co. and similar preparations); and (3) Isopropyl antipyrine, phenacetin, "persedon" (3-3-diethyl-2-4diheto-tetrahydro-pyridine), caffeine ("saridone" [propylphenazone, phenacetin, and caffeine], implicated in European "saridone nephritis").

Obviously acetylsalicylic acid cannot be blamed for "saridone nephritis," caffeine for "Tab. Cod. Co. nephritis," nor codeine for "A.P.C. nephritis" or " saridone nephritis." Since phenacetin is the only drug common to the innumerable drug combinations of this type it is not surprising that the condition has come widely to be called " phenacetin nephritis." Recently some authors have for preference used the term "analgesic abuse," but this is no more "terminologically exact" than any other, since caffeine-a common constituent of many preparations-is not an analgesic at all but a stimulant. For the pedant the exact terminology might well be " chronic interstitial nephritis with papillary necrosis in persons abusing preparations containing phenacetin among a diversity of other drugs, including analgesics, antipyretics, and stimulants."

Incidentally, there are those who maintain that "chronic interstitial nephritis with papillary necrosis" is simply a variant of chronic pyelonephritis, and that the abuse of phenacetin-containing preparations is entirely unrelated to the renal disease. In this connexion $I$ have just seen the condition in a woman who consumed 6-12 Tabs. Cod. Co. daily for 10-15 years for a painful disorder unrelated to the kidneys. Quite emphatically, there was not a shred of evidence clinically or at necropsy that she ever had acute or chronic pyelonephritis.

For the record, the "commercial preparation containing phenacetin" used by the patient reported by us (B.M.F., 1 February, p. 288) was very similar to Tab. Cod. Co. ; it contained acetylsalicylic acid $250 \mathrm{mg}$., phenacetin $250 \mathrm{mg}$., codeine phosphate $10 \mathrm{mg}$.I am, etc.,

$$
\begin{aligned}
& \text { Group Pathological Laboratory, } \\
& \text { St. David's Hospital, } \\
& \text { Cardiff. }
\end{aligned}
$$

SIR,-In the case of chronic interstitial nephritis with papillary necrosis presented (1 February, p. 288) by Drs. N. G. Sanerkin and Corinna Weaver as a case of chronic phenacetin nephropathy, caused by the taking of approximately $8 \mathrm{~kg}$. of phenacetin over a period of 40 years, the other ingredients in the commercial preparation containing the phenacetin which the patient took are unfortunately not stated.

Could the names of the other ingredients please be given and the estimated quantities of each consumed over 40 years be stated ? Is it possible that one of the other ingredients of the preparation taken could have caused or played a part in causing the chronic renal disease found at post-mortem?

Patients who consume phenacetin in excessive quantities for many years usually take 